\title{
Cuticular ridge patterns applied for identifying adult female worms of Haemonchus species with various vulvar morphological types in infected native goats in Laos
}

\author{
Vongnady, K. ${ }^{1}$, Rucksaken, R. ${ }^{1}$, Mangkit, B. ${ }^{1 *}$ \\ ${ }^{1}$ Department of Veterinary Technology, Faculty of Veterinary Technology, Kasetsart University, Bangkhen Campus, Bangkok 10900, Thailand \\ *Corresponding author: fvetbdm@ku.ac.th
}

\section{ARTICLE HISTORY}

Received: 28 January 2021

Revised: 26 June 2021

Accepted: 27 June 2021

Published: 31 July 2021

\begin{abstract}
Species of the blood sucking nematode Haemonchus are a main problem in the small ruminant industry worldwide. Haemonchus worms were taken from 68 infected native goats slaughtered in three provinces of Laos in June and July 2019. Cuticular ridge patterns were used for the first time to identify adult female Haemonchus spp. and their vulvar morphs were characterized. The results showed that the variations in vulvar morphology of female Haemonchus spp. presented a knobbed morph as the dominant morphotype and predominant linguiform $B$ subtype was also detected. In total, 270 selected female worms from each vulvar morph type were examined based on their cuticular ridge patterns in cross sections at positions of the esophageal-intestinal junction (EI), the $4 \mathrm{~mm}$ region from the anterior end $(4 \mathrm{~mm})$, and the mid-body (MB). Only Haemonchus contortus was identified and most worms had constant numbers of ridges at $\mathrm{EI}, 4 \mathrm{~mm}$, and $\mathrm{MB}$, namely 30,26 , and 22 ridges, respectively, accounting for $99.26 \%, 97.41 \%$, and $97.04 \%$, respectively, of worms detected, while the lowest variation in the number of ridges was at region El which is recommended as the single best position. Based on synlophe and ITS2 sequence analysis, it was assumed that $H$. contortus might dominate in the sample areas with the possible numbers of ridges of $H$. contortus females in the ranges $29-30,25-27$, and 21-23 for positions El, $4 \mathrm{~mm}$, and $\mathrm{MB}$, respectively. The cuticular ridge pattern was a useful character for identifying female Haemonchus species in this study and could be utilized as an affordable alternative method for epidemiological studies and as part of parasite control management in native goats of Laos.
\end{abstract}

Keywords: Cuticular ridge pattern; Haemonchus spp.; vulvar morph; ITS2; Laos.

\section{INTRODUCTION}

The world goat population continues to increase, exceeding one billion globally, with $90 \%$ of goats raised in Asia and Africa (Monteiro et al., 2018; Hegde, 2020) and particularly in the rural and remote areas of developing countries (Skapetas \& Bampidis, 2016). In the Lao People's Democratic Republic (Laos), goat production has doubled since 2011 (Windsor et al., 2018; Burns et al., 2019) and has progressively increased over consecutive years, with total numbers of 560,000, 588,000, 616,325 , and 639,715 head in 2016, 2017, 2018, and 2019, respectively (http://www.fao.org/faostat/en/\#data/QA). However, goats in Laos are not only a source of high protein food and cash income for poor families within the country, but the goat meat is also exported to neighboring countries such as Vietnam, and China (Burns et al., 2019).

Goat production in Laos must now deal with many factors including diseases caused by internal parasites (Wilson, 2007; Windsor et al., 2018). Haemonchus spp. are blood-feeding parasites known as one of the most important gastrointestinal nematodes of small ruminants as the causal agent of haemonchosis (Wang et al., 2017; Arsenopoulos et al., 2021). In Laos, Haemonchus spp. are the most prevalent compared to other endoparasites (Sato et al., 2014: Windsor et al., 2018). Specifically, Haemonchus contortus is recognized as the most harmful of these worms and is highly pathogenic in goats and sheep (Suarez et al., 2017; Selemon, 2018; Höglund et al., 2019) being the main cause of animal health problems with predominant signs globally being anemia and death (Besier et al., 2016; Kandil et al., 2017; Wang et al., 2017; Selemon, 2018; Höglund et al., 2019) including in Laos (Windsor et al., 2018). Furthermore, $H$. contortus has developed resistance to various anthelmintics, causing problems for small ruminant production (Peter \& Chandrawathani, 2005; Kotze \& Prichard, 2016) and causing major economic losses globally (Wang et al., 2017; Windsor et al., 2018; Douanne et al., 2019; Sallé et al., 2019).

Reliable identification of Haemonchus species in goats provides invaluable epidemiological data that can lead to effective control strategies for haemonchosis. Normally, the 
eggs of Haemonchus spp. and other strongylids show a similar morphology and it is difficult to differentiate them under a microscope (Schnieder et al., 1999; Craig, 2018). This can result in unreliable identification due to the unclear larval morphology in combination with genus and species identification of the infective stage larvae being based on standard larval culture techniques which takes considerable time and requires highly skilled personnel (Douanne et al., 2019; Schnieder et al., 1999). Molecular methods such as polymerase chain reaction (PCR) are more sensitive and accurate compared to microscopic diagnosis (Ljungström et al., 2018), but disadvantages are that PCR is somewhat costly both in reagents and other relevant tools (Jacquiet et al., 1997; Selemon, 2018). Consequently, some countries where budgets are limited, particularly in developing countries, may not be able to offer this technology to farmers. Therefore, it is necessary to identify other reliable morphological characters of adult worms for the identification of Haemonchus species as an alternative.

Most commonly, the morphology of adult male Haemonchus worms based on spicule measurements (Lichtenfels et al., 1988; Lichtenfels et al., 1994) and a linear discriminant function (Jacquiet et al., 1997; Achi et al., 2003) are used for species identification. However, the measured values obtained may overlap as often occurs among the two main species, $H$. contortus and $H$. placei (Silva et al., 2015; Vongnady et al., 2020b), resulting in potential misidentification. The cuticular ridge pattern or synlophe (Lichtenfels et al., 1994; Lichtenfels \& Pilitt, 2000) is known as one of the most valuable morphological characters mainly used for identifying trichostrongylids to the species level in ruminants (Lichtenfels et al., 1988; Lichtenfels et al., 1994; Lichtenfels \& Pilitt, 2000; Gharamah et al., 2011). This character has been applied successfully for classifying Haemonchus spp. collected from different ruminant species and areas including the USA (Lichtenfels et al., 1994), Malaysia (Rahman \& Abd Hamid, 2007; Gharamah et al., 2011), Brazil (Silva et al., 2015), Thailand (Vongnady et al., 2020a, 2020b), and Laos (Vongnady et al., 2020b).

In Laos, cuticular ridge patterns have been recorded in adult male Haemonchus worms derived from native goats to address issues of species identification (Vongnady et al., 2020b); however, similar details for adult female Haemonchus worms have not yet been reported. Thus, there is merit in using this character as an alternative tool for identifying female Haemonchus worms to enhance the effective and sustainable control of Haemonchus spp. in endemic areas in Laos, particularly if no adult male worms are available or the male structures are inappropriate and damaged. Therefore, the objective of this first study was to identify adult female Haemonchus worms collected from native goats reared in different regions of Laos by observing the cuticular ridge patterns in cross sections on the surface body of these nematodes. In addition, the type of vulvar process of all female worms was classified. Furthermore, molecular approaches based on the second internal transcribed spacer (ITS2), were used to confirm Haemonchus spp. when some specimens of female worms had unclear cuticular ridge patterns and the variations in their ridges prevented positive identification based on visual examination.

\section{MATERIALS AND METHODS}

\section{Ethics approval}

This research involved parasite collection from goats' abomasa. Before conducting this process, the relevant protocols were evaluated and approved by the Kasetsart
University Institutional Animal Care and Committee Use (approval no. ACKU62-VTN-006), Kasetsart University, Bangkok, Thailand.

\section{Studied areas and parasites}

The 3338 adult female Haemonchus worms used for morphological study were obtained from the same infected goats (68/103) as described in Vongnady et al. (2020b) during the same period (June-July 2019), as shown in Table 1.

Three provinces in Laos (Figure 1) were sampled (Luang Prabang, Savannakhet, and Champasak) based on distance and the number of goat populations including selected goats as explained by Vongnady et al. (2020b). The climate at all locations is mostly tropical with a seasonal monsoon (Wilson, 2007). Worm discovery was performed following the procedure described by Vongnady et al. (2020b). Collected adult female worms were identified (Figure 2a, b, c, d, e, f) and isolated from male worms based on viewing under a stereomicroscope (Olympus Corporation, Japan) as described by MAFF (1971), Soulsby (1982), Kumsa et al. (2008), Lichtenfels et al. (1994), and Mangkit et al. (2014). All Haemonchus females were transferred to $70 \%$ ethyl alcohol and kept in a refrigerator $\left(4^{\circ} \mathrm{C}\right)$ until further processing.

\section{Determination of vulvar morphological types}

The adult female Haemonchus worms used for classification based on vulvar morph types were observed under stereomicroscopy following the guidelines in Roberts et al. (1954), Rose (1966), LeJambre \& Whitlock (1968), Lichtenfels et al. (1994), Kumsa et al. (2008), Akkari et al. (2013), and Vongnady et al. (2020a). First, three main vulvar morphs were identified as either linguiform (with a supra vulvar flap), knobbed (with a knob-like vulvar process), or smooth (without any vulvar process) vulvar morphs while 1020 linguiform vulvar flaps were then classified as sublinguiform. All types of vulvar morphs were counted and recorded (Table 1 and Figure 3).

\section{Morphological identification using cuticular ridge patterns}

In the three provinces of Laos, one to four adult female Haemonchus worms were randomly chosen from each vulvar process type from individually infected goats. Thus, 270 worms (90 worms from each province) were examined for cuticular ridge patterns (number of ridges) in cross sections. Study of the cuticular ridge patterns was according to the protocol originally described by Lichtenfels et al. (1986) and Lichtenfels et al. (1994) with some minor modifications reported by Vongnady et al. (2020a, 2020b). The selected regions for study of the synlophe in each worm were at three main regions: the esophageal-intestinal junction (EI), $4 \mathrm{~mm}$ from the anterior end $(4 \mathrm{~mm})$, and mid-body (MB) (Figure 2a, b). The number of cuticular ridges in each position was observed under a compound light microscope (Carl Zeiss, Germany; Olympus Corporation, Japan). The references for the numbers of cuticular ridge patterns at positions EI, 4 $\mathrm{mm}$, and $\mathrm{MB}$ used in this study were obtained from previous publications for three main species: $H$. contortus, $H$. placei, and $H$. similis, as shown in Table 2.

\section{DNA extraction method, amplification, and sequencing}

Using information from the references regarding cuticular ridges mentioned earlier, 270 randomly chosen female worms were classified as $\mathrm{H}$. contortus based on their cuticular ridge patterns at positions $\mathrm{El}, 4 \mathrm{~mm}$, and $\mathrm{MB}$. In total, 15 of these worms presented variations in the number of ridges from constant ridges at positions $\mathrm{El}, 4 \mathrm{~mm}$, and $\mathrm{MB}$ of 29 , (25 and 27), and (21 and 23) ridges, respectively, and 14 of these worms (five, five, and four from Luang Prabang, Savannakhet, 
Table 1. Overall proportion and intensity, three main vulvar morph types, and linguiform vulvar subtypes of adult female Haemonchus worms in native goats from three provinces of Laos

\begin{tabular}{|c|c|c|c|c|c|c|c|c|c|c|c|c|}
\hline Provinces & $\begin{array}{c}\text { No. } \\
\text { of } \\
\text { hosts }\end{array}$ & $\begin{array}{c}\text { No. of } \\
\text { infected } \\
\text { hosts (\%) }\end{array}$ & $\begin{array}{c}\text { Density } \\
\text { of } \\
\text { worms(n) }\end{array}$ & $\begin{array}{c}\text { No. of } \\
\text { female } \\
\text { worms (\%) }\end{array}$ & $\begin{array}{l}\text { Linguiform } \\
\mathrm{n}(\%)\end{array}$ & $\begin{array}{c}\text { Knobbed } \\
\text { form } \\
n(\%)\end{array}$ & $\begin{array}{c}\text { Smooth } \\
\text { form } \\
n(\%)\end{array}$ & $\begin{array}{l}\text { LA } \\
n(\%)\end{array}$ & $\begin{array}{c}\text { LB } \\
n(\%)\end{array}$ & $\begin{array}{c}\text { LC } \\
n(\%)\end{array}$ & $\begin{array}{c}\mathrm{LI} \\
\mathrm{n}(\%)\end{array}$ & $\begin{array}{l}\text { LTEC } \\
\mathrm{n}(\%)\end{array}$ \\
\hline Luang Prabang & 31 & $21(67.74)$ & 2220 & 1081(48.69) & $226(20.91)$ & 853 (78.91) & $2(0.18)$ & $115(50.88)$ & $96(42.48)$ & $8(3.54)$ & $4(1.77)$ & $3(1.33)$ \\
\hline Savannakhet & 40 & $27(67.50)$ & 3511 & $1703(48.50)$ & $587(34.47)$ & $1108(65.06)$ & $8(0.47)$ & $247(42.08)$ & $324(55.20)$ & $3(0.51)$ & $10(1.70)$ & $3(0.51)$ \\
\hline Champasak & 32 & $20(62.50)$ & 1250 & $554(44.32)$ & $207(37.36)$ & $344(62.09)$ & $3(0.54)$ & $99(47.83)$ & $99(47.83)$ & 0 & $7(3.38)$ & $2(0.97)$ \\
\hline
\end{tabular}

$n$ : number of worms, LA, LB, LC, LI, and LTEC subtypes: Linguiform A, B, C, I, and TEC subtypes, respectively.

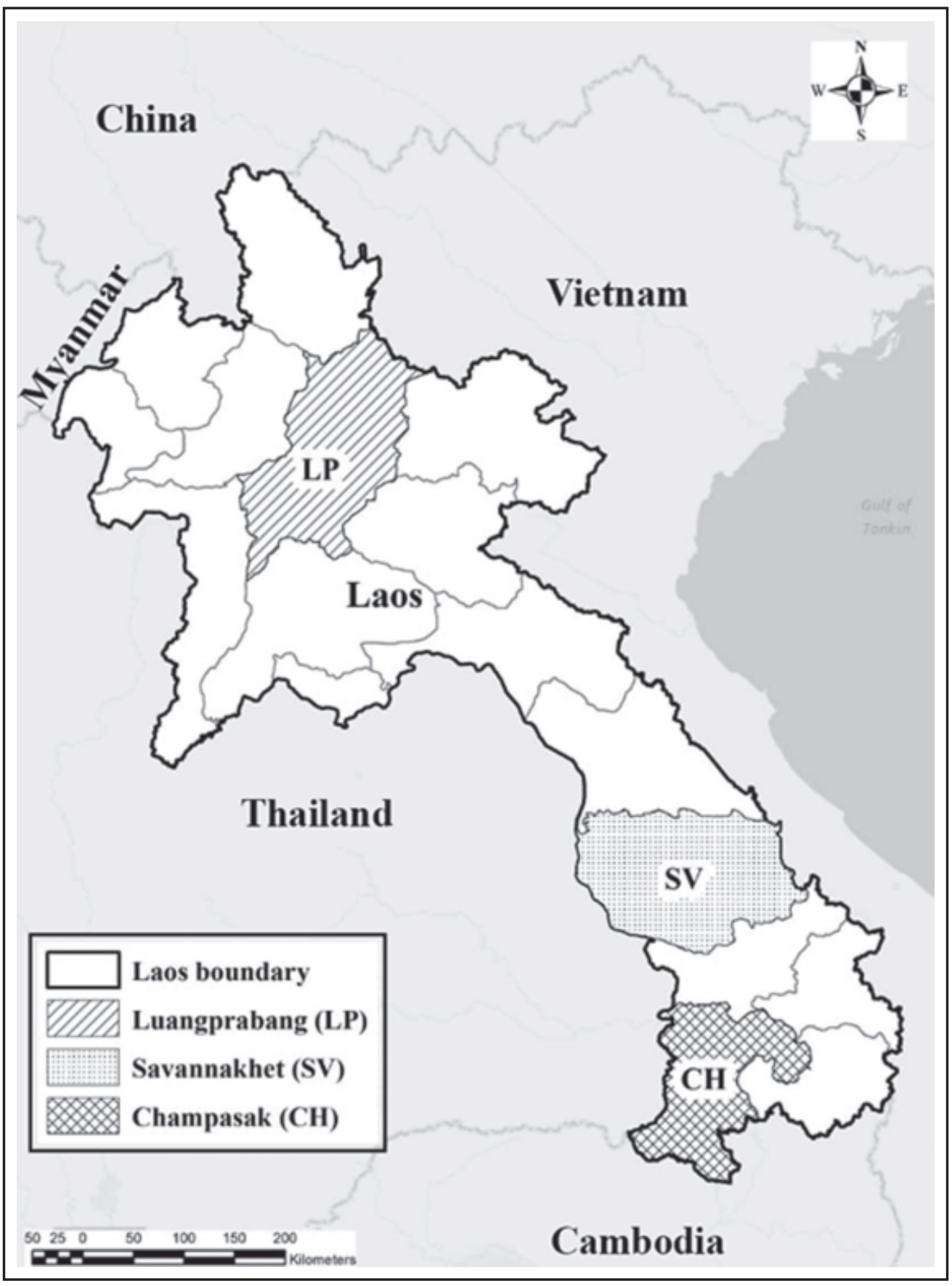

Figure 1. Map of Laos showing sampling sites of study areas. 


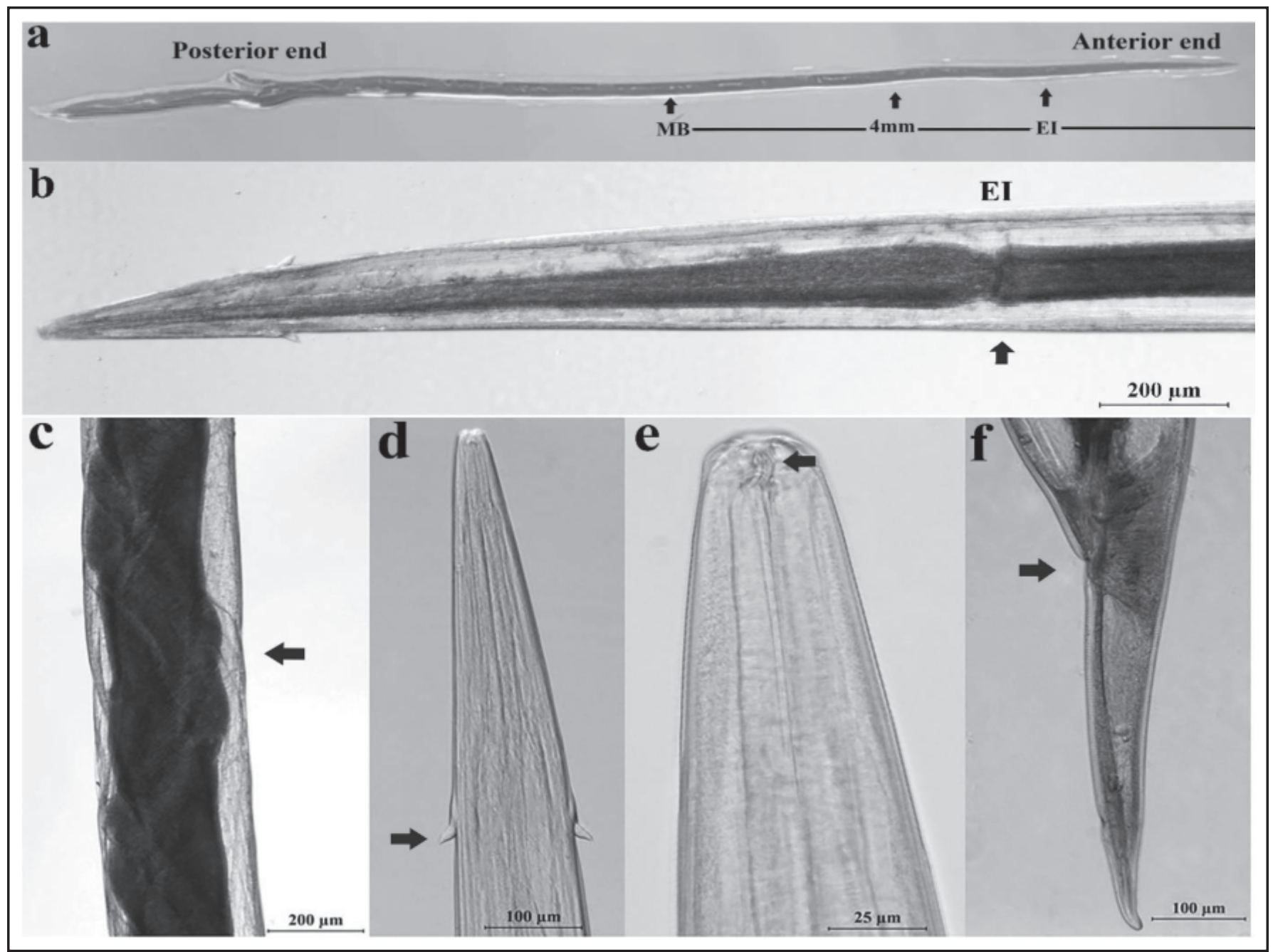

Figure 2. Morphology of adult female Haemonchus spp. from native goats in Laos. a: positions for cross sections at El, $4 \mathrm{~mm}$, and $\mathrm{MB}$; b: magnified El, c: barber pole appearance of females, $d$ : cervical papillae, e: dorsal lancet, f: posterior end of female tail with anus.

Table 2. The references for the numbers of cuticular ridge patterns used for identifying adult female Haemonchus species in native goats of Laos

\begin{tabular}{|c|c|c|c|c|}
\hline \multirow{2}{*}{ Cross sections } & \multicolumn{3}{|c|}{ Haemonchus spp. } & \multirow{2}{*}{ References } \\
\hline & H. contortus & H. placei & H. similis & \\
\hline Esophageal-intestinal (EI) junction & 30 & 34 & 34 & \multirow{2}{*}{ Lichtenfels et al., 1994} \\
\hline $4 \mathrm{~mm}$ & 25 & 30 & 30 & \\
\hline $4 \mathrm{~mm}$ & 26,24 & - & - & Rahman \& Abd Hamid, 2007 \\
\hline Esophageal-intestinal (EI) junction & 30 & 34 & 34 & \multirow{2}{*}{ Silva et al., 2015} \\
\hline Mid-body & 22 & Absent & 26 & \\
\hline Esophageal-intestinal (EI) junction & $29,30,31$ & - & - & \multirow{3}{*}{ Vongnady et al., 2020a } \\
\hline $4 \mathrm{~mm}$ & $25,26,27,28$ & - & - & \\
\hline Mid-body & $21,22,23$ & - & - & \\
\hline Esophageal-intestinal (EI) junction & 29,30 & - & - & \multirow{2}{*}{ Vongnady et al., 2020b } \\
\hline $4 \mathrm{~mm}$ & 26,27 & - & - & \\
\hline
\end{tabular}




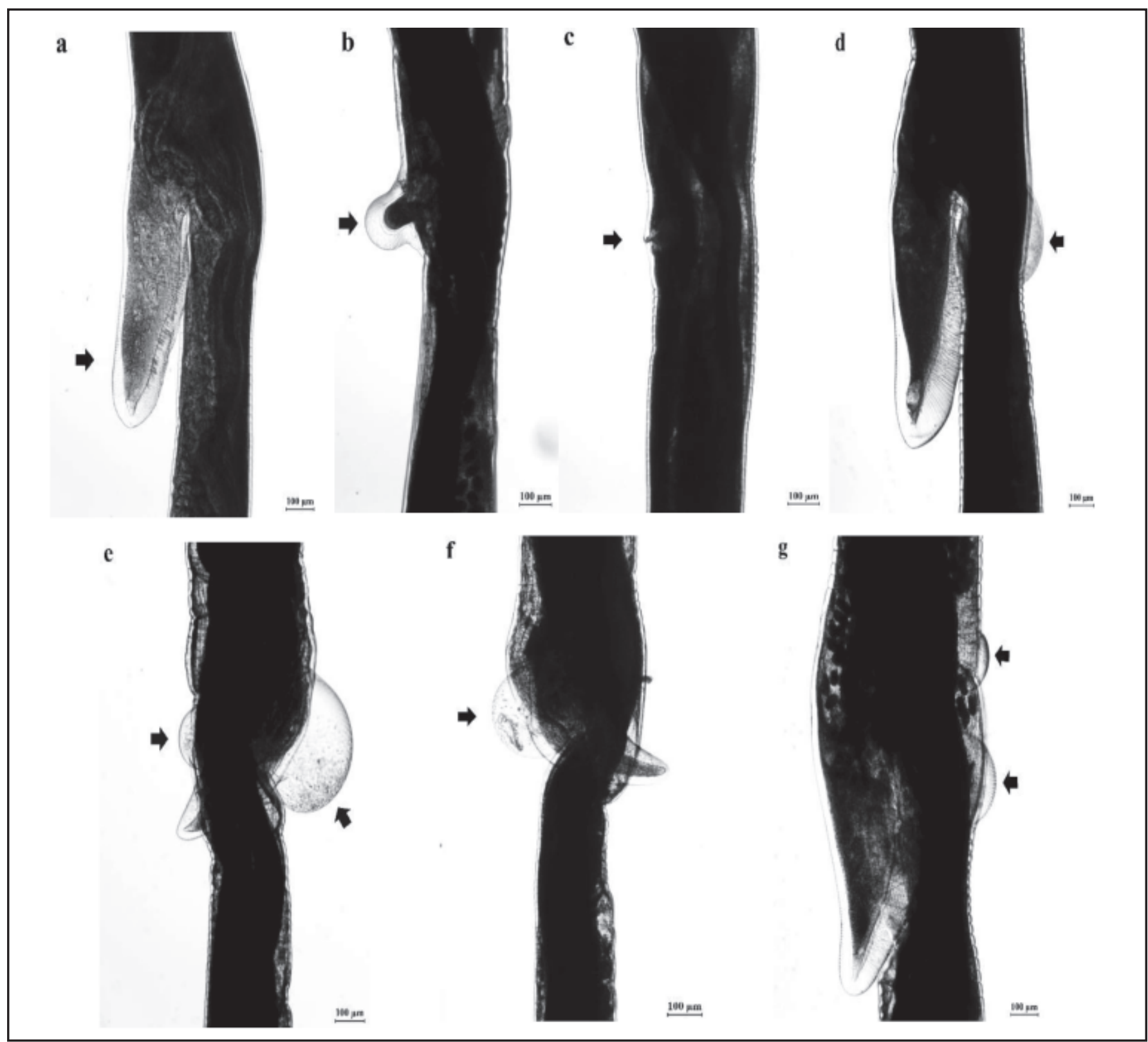

Figure 3. Vulvar morphological variations of adult female Haemonchus spp. in native goats of Laos. a: linguiform vulvar process or LB subtype (without cuticular inflation), b: knobbed vulvar process, c: smooth vulvar morph, d: LA subtype (one cuticular inflation), e: LC subtype (two cuticular inflations), f: LI subtype (cuticular inflation arising from the linguiform process), g: LTEC subtype (two extra cuticular inflations).

Table 3. Overall proportion of adult female Haemonchus spp. identified based on cuticular ridge patterns in three positions from native goats of Laos

\begin{tabular}{|c|c|c|c|c|c|c|c|c|c|c|c|c|c|c|c|c|}
\hline \multirow{3}{*}{ Provinces } & \multirow{3}{*}{$\begin{array}{l}\text { No. of } \\
\text { Worms }\end{array}$} & \multicolumn{15}{|c|}{ No. of female Haemonchus species identified using synlophes in three positions } \\
\hline & & \multicolumn{5}{|c|}{$\mathrm{EI}$} & \multicolumn{5}{|c|}{$4 \mathrm{~mm}$} & \multicolumn{5}{|c|}{$\mathrm{MB}$} \\
\hline & & $\mathrm{Hc}$ & $\mathrm{Hp}$ & Hs & US & HcVNR & $\mathrm{Hc}$ & $\mathrm{Hp}$ & Hs & US & HcVNR & $\mathrm{Hc}$ & $\mathrm{Hp}$ & Hs & US & HcVNR \\
\hline $\begin{array}{l}\text { Luang } \\
\text { Prabang }\end{array}$ & 90 & 90 & 0 & 0 & 0 & 1 & 90 & 0 & 0 & 0 & 1 & 90 & 0 & 0 & 0 & 2 \\
\hline Savannakhet & 90 & 90 & 0 & 0 & 0 & 0 & 90 & 0 & 0 & 0 & 1 & 90 & 0 & 0 & 0 & 3 \\
\hline Champasak & 90 & 90 & 0 & 0 & 0 & 1 & 90 & 0 & 0 & 0 & 5 & 90 & 0 & 0 & 0 & 3 \\
\hline Total (n) & 270 & 270 & 0 & 0 & 0 & 2 & 270 & 0 & 0 & 0 & 7 & 270 & 0 & 0 & 0 & 8 \\
\hline (\%) & & 100 & 0 & 0 & 0 & 0.74 & 100 & 0 & 0 & 0 & 2.59 & 100 & 0 & 0 & 0 & 2.96 \\
\hline
\end{tabular}

$\mathrm{n}$ : number of worms, El: esophageal-intestinal junction, $4 \mathrm{~mm}: 4 \mathrm{~mm}$ region from the anterior end, MB: mid-body position, Hc: $H$. contortus, Hp: $H$. placei, $\mathrm{Hs}$ : H. similis, US: unidentified species, HcVNR: variable number of ridges of $H$. contortus ( 29 ridges for $\mathrm{El}, 25$ and 27 for $4 \mathrm{~mm}$, and 21 and 23 ridges for MB). 
and Champasak provinces, respectively) in the $255 \mathrm{H}$. contortus females presented 30,26 , and 22 ridges at positions $E I, 4$ $\mathrm{mm}$, and $M B$, respectively were proven based on PCR-ITS2 (Table 4). Thus, in total, 29 female $H$. contortus were included for DNA extraction and further genetic analysis (Table 5).

Genomic DNA (gDNA) was extracted from the anterior fragments before the region of female reproductive organs in each worm after completed synlophes using a GF-1 Tissue DNA Extraction Kit (Vivantis Technologies Sdn. Bhd., Malaysia) according to the manufacturer's instructions with a few modifications as described by Vongnady et al. (2020b). All extracted gDNA was kept at $-20^{\circ} \mathrm{C}$ for use in PCR. The ITS2 segment of the adult female Haemonchus worms was amplified using the primer sets originally reported by Stevenson et al. (1995): NC1_F: 5-ACGTCTGGTTCAGGGTTGTT-3 and NC2_R:5-TTAGTTTCTTTTCCTCCGCT-3). The PCR conditions were as described by Vongnady et al. (2020a, 2020b). The PCR cycle conditions were conducted as referred by Gharamah et al. (2012), Mangkit et al. (2014), and Vongnady et al. (2020a). The successfully amplified PCR products (321bp) were electrophoresed, stained with DNA safe stain, and photographed under a UV light, as described by Vongnady et al. (2020a, 2020b). Then, all ITS2 amplicons were directly purified and automatically sequenced using forward and reverse primers at Macrogen (South Korea).

Species confirmation based on DNA sequencing, some genetic data analyses, and phylogenetic analysis

The 29 new rDNA ITS2 sequences obtained from the female $H$. contortus samples from the three provinces of Laos were edited manually and aligned using CLUSTAL $W$ available in the MEGA version 7.0 (Kumar et al., 2016).

All sequences were preliminarily blasted and compared with another sequence deposited in the GenBank (http:// www.ncbi.nlm.nih.gov/blast/Blast.cgi) utilizing the BLAST tool. All confirmed 29 sequences were known as $H$. contortus and then designated as genotypes. All genotypes (231 bp) were analyzed together with other $H$. contortus sequences (231 bp) available in GenBank depending on the methods selected to confirm $\mathrm{H}$. contortus. The nucleotide polymorphism analyses of all genotypes were carried out using the CLUSTAL W program together with the BioEdit software (Hall, 1999) compared with a reference sequence of $H$. contortus (accession number X78803) including other published sequences of H. contortus (KP090290, JX869067, JX869072, KP101363, MH481574, MH481598, EU086390, MT424901, MT424902, MT424903, MT682957) and H. placei (KF364623, MH481601, KC503916, $\mathrm{X78812}$ ) (Table 8), while pairwise comparisons of all genotypes were also conducted using the BioEdit software compared with published $H$. contortus and $H$. placei sequences as mentioned above for nucleotide polymorphism analyses (Table 7). A phylogenetic tree based on the neighbor-joining (NJ) method using a distance-based analysis (the Kimura-2 parameter model) was applied to confirm $H$. contortus genotypes. NJ was carried out using the MEGA 7.0 software package with 1000 bootstrap replicates. The ITS2 sequences of H. placei (KF364623, MH481601, KC503916, and X78812) were defined as the outgroup while 34 ITS2 sequences of $H$. contortus used retrieved from the GenBank from different areas and hosts are presented in Figure 5 for all accession numbers (KP101364, AB908961, LC360146, MT682957, KC415117, KF364629, KY305781, KC632567, X78803, EU086378, MH481574, MH481598, HQ389229, KP090289, KP090290, KP090293, JX869067, JX869072, JX869074, KP101363, EU086390, LC360153, KJ724317, KJ724250, KC503915, KJ188203, AB682686, KC998713, MT424901, MT424902, MT424903, JX901156, JX901146, JX901144).

\section{Statistical analysis}

All the data including the number of worms, vulvar morphs, and ridges obtained from Haemonchus worms in native goats from three provinces were stored using the Microsoft Excel software package. Descriptive statistics (average, percentage, median, minimum and maximum values) were calculated and inferential statistics were analyzed using the $\mathrm{R}$ software, version 3.6.1 (R Core Team, 2019). Based on the cuticular ridge patterns and genetic information analyzed in this study, $H$. contortus was confirmed and as expected it was the only species found in this research. Thus, the data of cuticular ridges of the 270 adult female $H$. contortus were imported for statistical analysis. Because of non-normal data distributions detected, non-parametric statistical analysis was applied using the Kruskal-Wallis test, and the median values of the number of cuticular ridge at the same position in each province were compared based on a p-value of less than 0.05 being considered as a significant difference.

\section{RESULTS}

\section{Parasite infection and worm burdens}

Of the 103 native goats from the three provinces of Laos examined, $66.02 \%$ (68/103) were positive for adult female Haemonchus infection. The highest proportion was in the Luang Prabang and Savannakhet provinces ( 67\%), followed by Champasak province (62.5\%), as displayed in Table 1 . Of the total 3338 female worms discovered, the Savannakhet and Luang Prabang provinces had the highest intensity of female Haemonchus worms in almost equal proportions $(\sim 48 \%)$ while the lowest density of worms was in Champasak province (44.32\%).

Vulvar process morphology of adult female Haemonchus spp. Overall, 3338 adult female Haemonchus worms in three provinces were examined microscopically based on vulvar morphological patterns. The knobbed vulvar morphs of female worms were predominant $(69.02 \%)$, followed by linguiform vulvar morphs (30.57\%), and the least proportion was smooth vulvar morphs. Knobbed vulvar morphs dominated in the three provinces with the highest proportion (78.91\%) in Luang Prabang province, while the highest proportion of linguiform and smooth vulvar morphs (37.36\% and $0.54 \%$, respectively) was in Champasak province (Table 1).

All five subtypes were detected of linguiform female Haemonchus worms: Linguiform A (LA), Linguiform B (LB), Linguiform C (LC), Linguiform I (LI), and Linguiform TEC (LTEC) subtypes and they were distributed in the three provinces, except for the LC subtype that was not recovered in Champasak province. In total, 1020 linguiform female worms in the three provinces had the LB subtype as the most dominant type (50.88\%), followed by the LA subtype $(45.20 \%)$, the LI subtype $(2.06 \%)$, LC subtype (1.08\%), and the LTEC subtype $(0.78 \%)$. In Luang Prabang and Savannakhet provinces, the LA and LB subtypes had the highest proportions $(50.88 \%$ and $55.20 \%$, respectively) while Champasak province had equal proportions of the LA and LB subtypes (47.83\%). However, the LTEC subtype was the least common among the three provinces (Table 1 and Figure 3).

Identification of female Haemonchus species with cuticular ridge patterns in cross sections

In total, 270 female Haemonchus worms with different vulvar morphs in three provinces of Laos were identified based on their cuticular ridges in the regions $\mathrm{El}, 4 \mathrm{~mm}$, and MB (Table 3 and 4). According to the cuticular ridge references 
Vongnady et al. (2021), Tropical Biomedicine 38(3): 294-310

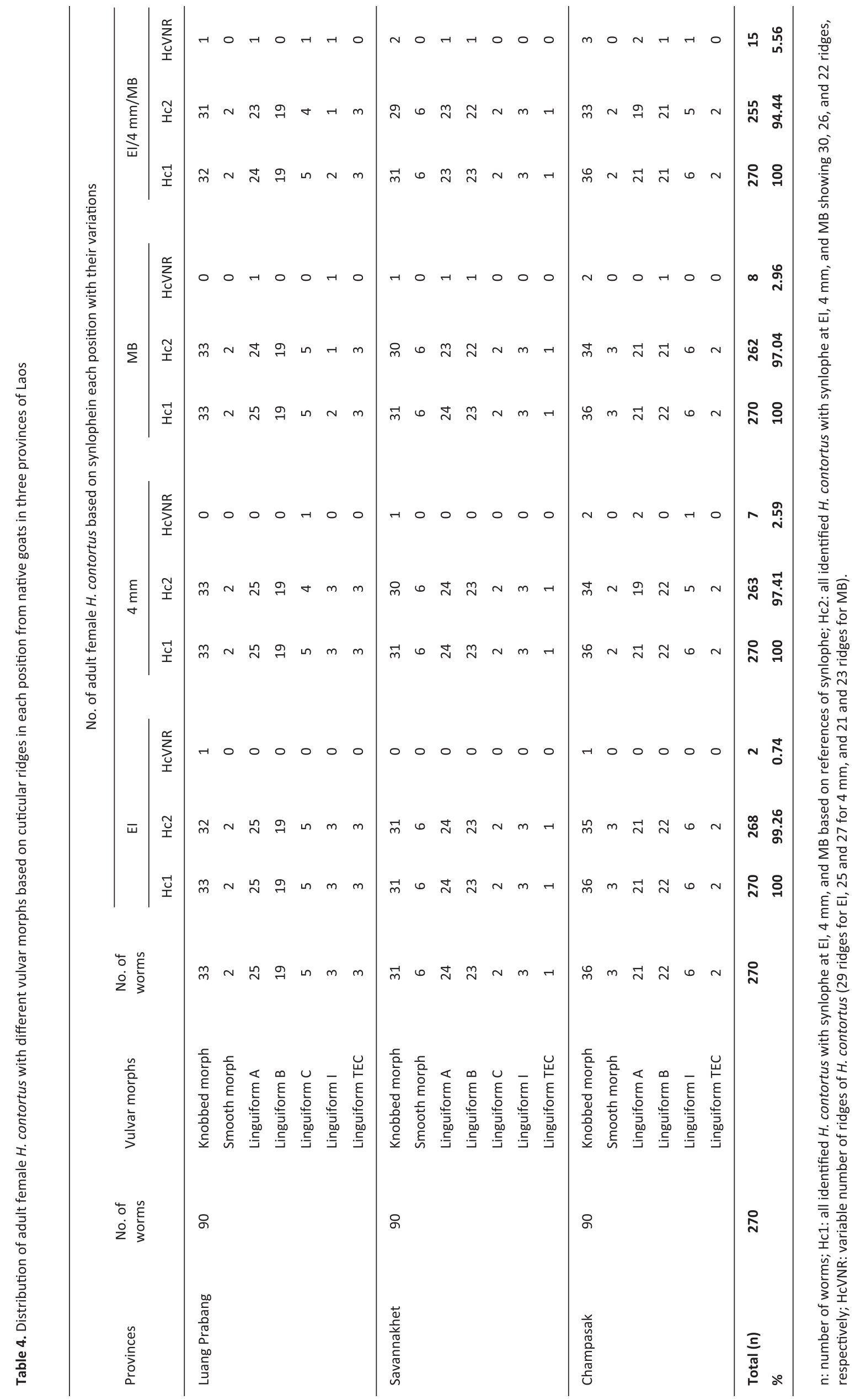




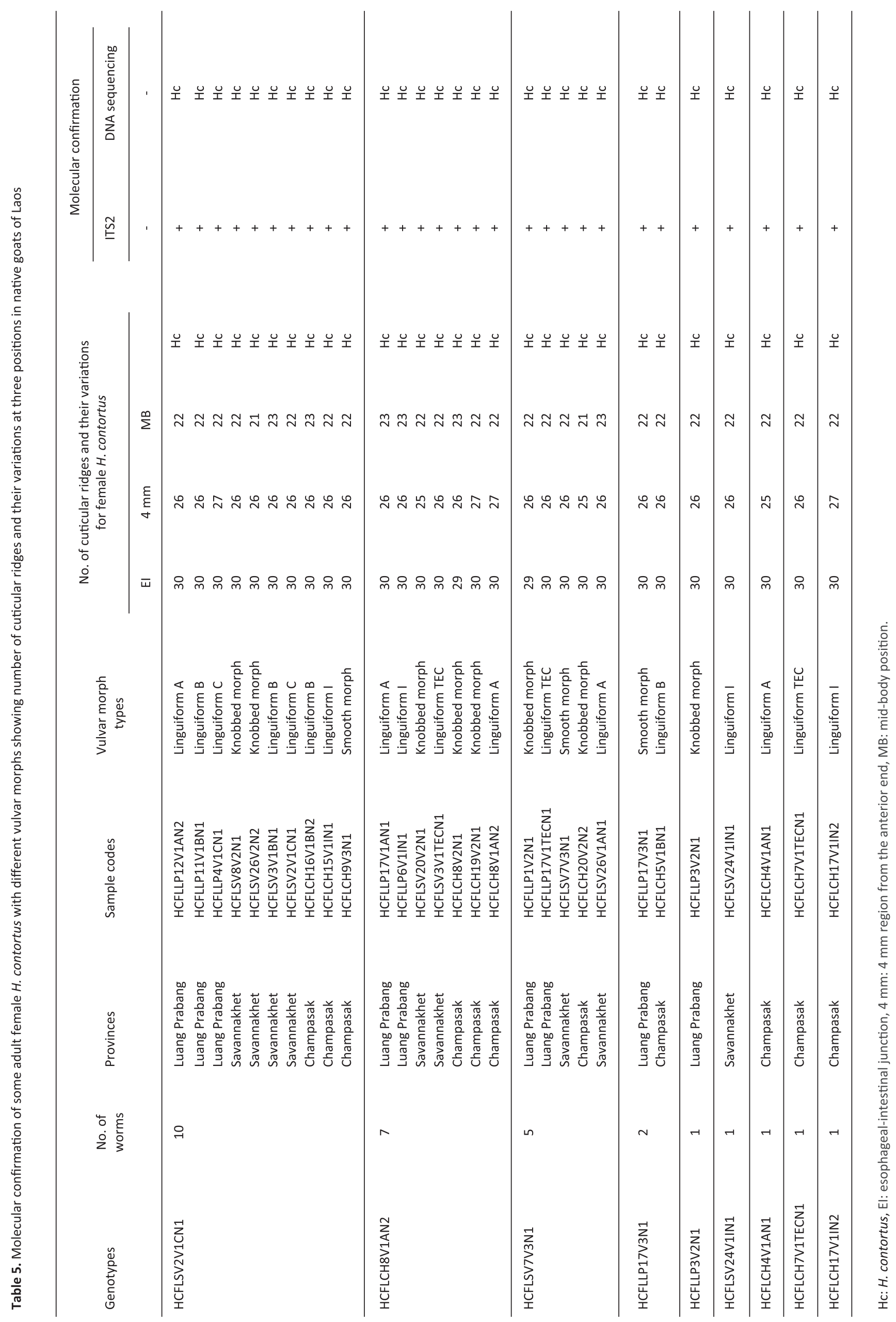




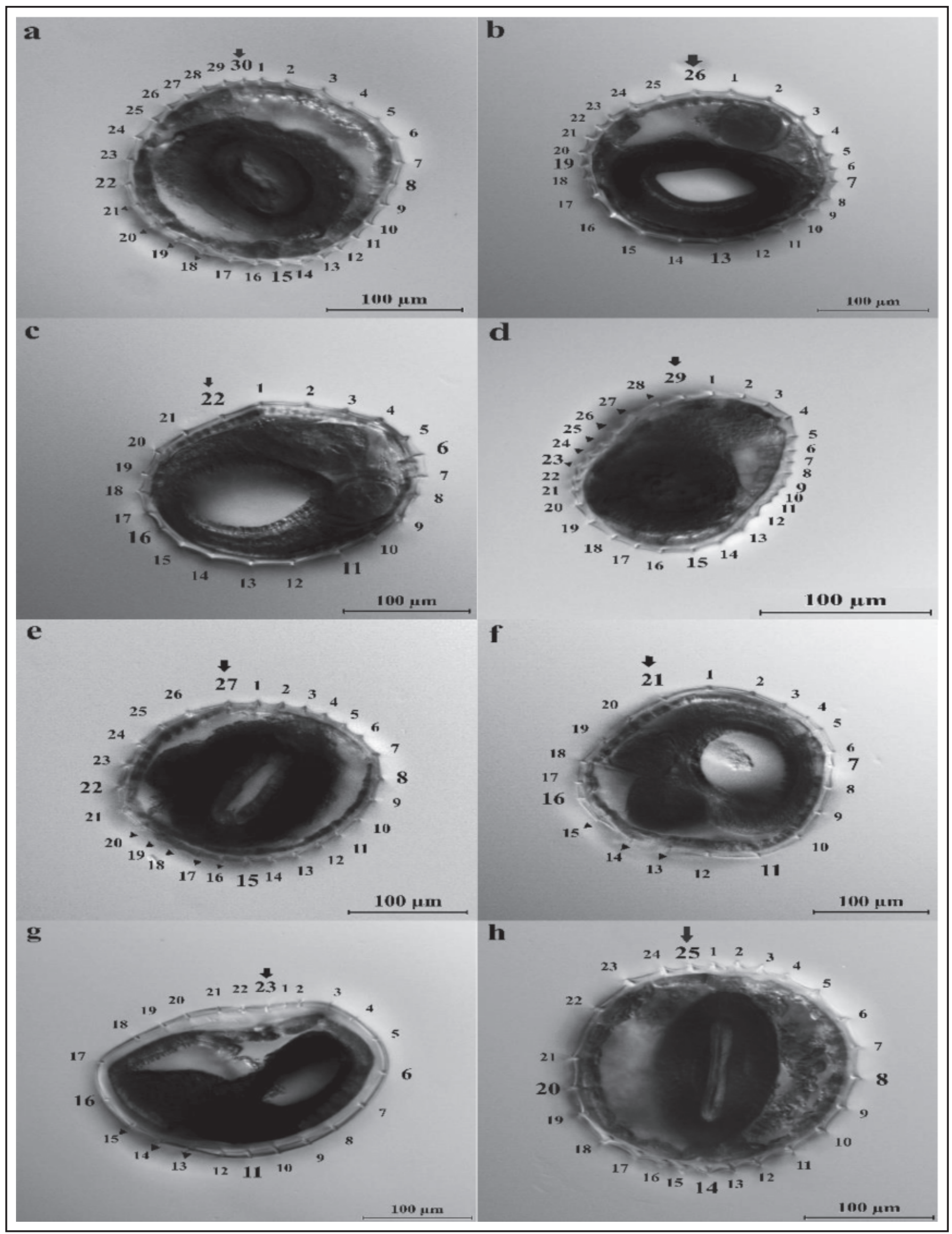

Figure 4. Number of cuticular ridges in cross sections of adult female $H$. contortus in native goats from three provinces of Laos (ac) and their variations (d-h). a: El (30 ridges), b: $4 \mathrm{~mm}$ (26 ridges), c: MB (22 ridges); d: El (29 ridges), e: $4 \mathrm{~mm}$ (27 ridges), f: MB (21 ridges), g: MB (23 ridges), h: $4 \mathrm{~mm}$ (25 ridges). 


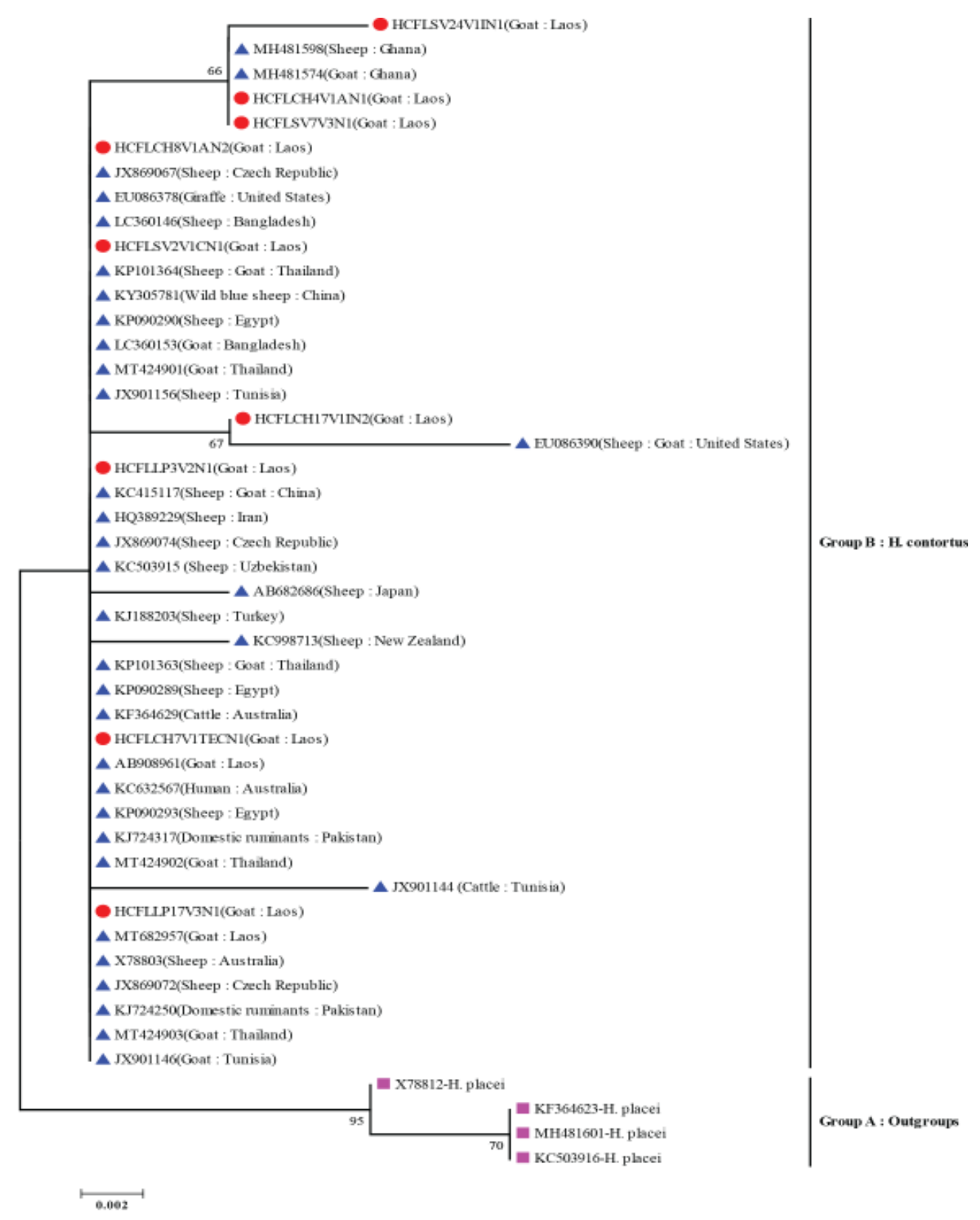

Figure 5. Phylogenetic relationships using NJ method based on ITS2 region of nine $H$. contortus genotypes in native goats of Laos analyzed with other $H$. contortus sequences from various areas and hosts deposited in GenBank compared with four $H$. placei sequences as outgroups.

applied at the three main positions, the results in the present study revealed $100 \%$ of female worms from all areas with several vulvar types were $H$. contortus, while Haemonchus placei, Haemonchus similis, and an unidentified species were not found (Table 3). In Tables 3 and 4, most female $H$. contortus had constant ridges at positions $\mathrm{El}, 4 \mathrm{~mm}$, and $\mathrm{MB}$ presenting 30 (99.26\%), 26 (97.41\%), and 22 (97.04\%) ridges, respectively, while the variations in numbers of cuticular ridges at positions El, $4 \mathrm{~mm}$, and $\mathrm{MB}$ were detected as $0.74 \%$ (two specimens with 29 ridges), 2.59\% (seven specimens with 25 and 27 ridges), and $2.96 \%$ (eight specimens with 21 and 23 ridges), respectively. However, when all three positions of the synlophes were considered, $94.44 \%$ of female worms were classified as $H$. contortus with $5.56 \%$ variation (Table 4 ). Based on the Kruskal-Wallis test utilized to compare the number of cuticular ridges obtained from the 270 female $H$. contortus in each position sampled in the three provinces, the numbers of cuticular ridges among the three provinces at the same positions were not significantly different. As shown in Table 6 , the median numbers of ridges for each province at regions $\mathrm{El}, 4 \mathrm{~mm}$, and $\mathrm{MB}$ were 30,26 , and 22 ridges, respectively.

\section{Species confirmation of $\boldsymbol{H}$. contortus using ITS2}

The PCR products of the ITS2 region belonging to 29 adult female $H$. contortus were amplified successfully with the expected sizes of $321 \mathrm{bp}$ compared with the DNA marker. After DNA sequence editing, alignment, and preliminary blasting, all 29 ITS2 sequences showed the $231 \mathrm{bp}$ and were identified as $H$. contortus, and nine genotypes of $H$. contortus were created. All $H$. contortus genotypes were deposited in GenBank with the accession numbers: MZ297602-MZ297610 
Vongnady et al. (2021), Tropical Biomedicine 38(3): 294-310

Table 6. Comparison between numbers of cuticular ridges at three positions of adult female $H$. contortus from native goats among three provinces of Laos

\begin{tabular}{|c|c|c|c|c|c|c|c|c|}
\hline Cuticular ridge patterns & Provinces & $\mathrm{n}$ & Mean & SD & Median & Min-Max & Chi-squared test & $\mathrm{p}$-value \\
\hline \multirow{3}{*}{$\begin{array}{l}\text { Esophageal-intestinal } \\
\text { junction (El) }\end{array}$} & Luang Prabang & 90 & 29.99 & 0.11 & 30.00 & $(29-30)$ & 2.02 & 0.365 \\
\hline & Savannakhet & 90 & 30.00 & 0.00 & 30.00 & $(30-30)$ & & \\
\hline & Champasak & 90 & 29.98 & 0.15 & 30.00 & $(29-30)$ & & \\
\hline \multirow{3}{*}{$\begin{array}{l}4 \mathrm{~mm} \text { region from its } \\
\text { anterior end }(4 \mathrm{~mm})\end{array}$} & Luang Prabang & 90 & 26.01 & 0.24 & 26.00 & $(25-27)$ & 2.45 & 0.294 \\
\hline & Savannakhet & 90 & 25.97 & 0.18 & 26.00 & $(25-26)$ & & \\
\hline & Champasak & 90 & 26.01 & 0.24 & 26.00 & $(25-27)$ & & \\
\hline \multirow{3}{*}{$\begin{array}{l}\text { Mid-body position } \\
\text { (MB) }\end{array}$} & Luang Prabang & 90 & 22.02 & 0.15 & 22.00 & $(22-23)$ & 0.221 & 0.895 \\
\hline & Savannakhet & 90 & 22.01 & 0.18 & 22.00 & $(21-23)$ & & \\
\hline & Champasak & 90 & 22.02 & 0.21 & 22.00 & $(21-23)$ & & \\
\hline
\end{tabular}

$\mathrm{n}$ : number of worms, SD: standard deviation, Min: minimum, Max: maximum, $\mathrm{p}<0.05$ is considered as significantly different.

shown in Table 8 . Whereas, multiple alignments of the nine genotypes were compared with the main reference sequences of $H$. contortus (X78803). In total, ten variable nucleotide positions were detected at $4,10,18,21,22,59$, $63,78,123$, and 196. Among these positions, six were transversions (two: $A<->C$; two: $A<->T$; one: $C<->G$; one: $G<->T$ ) at nucleotide positions $(4,10),(18,196),(21)$, and $(59)$, respectively, and four transitions were detected (four: $\mathrm{C}<->\mathrm{T}$ ) at positions 22, 63, 78, and 123; these were also aligned together with other sequences retrieved from GenBank (nos.11-21) and 12 polymorphic sites were discovered with two transitions additionally diagnosed (one: $\mathrm{C}<->\mathrm{T}$; one: $A<->G$ ) for positions 40 and 83 , respectively. For sequence alignments of $H$. contortus and $H$. placei, the results showed that the fixed nucleotide differences at positions 24, 205, and 219 were found specifically in $H$. placei (Table 8).

The percentage nucleotide identity of the nine $H$. contortus genotypes in Laos was in the range $95.60 \%-99.50 \%$ with a mean score of $97.80 \%$. These genotypes were compared with reference sequences of $H$. contortus from GenBank (X78803, KP090290, JX869067, JX869072, KP101363, MH481574, MH481598, EU086390, MT424901, MT424902, MT424903, and MT682957) and their similarities were in the range $96.10 \%$ $100 \%$ with a mean score of $98.59 \%$. In addition, all nine genotypes were compared with four reference sequences of H. placei (KF364623, MH481601, KC503916, and X78812) and had an average identity of $96.60 \%$ (range $95.60 \%-97.80 \%$ ), as shown in Table 7.

The phylogenetic tree built using the NJ analysis of the ITS2 $\mathrm{H}$. contortus genotypes in Lao goats was clustered in two main groups (Figure 5). All nine genotypes belonging to $H$. contortus in the present research were related to $H$. contortus from several areas and animal hosts deposited in GenBank and presented in group B with a mean identity score of $98.13 \%$ in the range $95.60 \%-100 \%$ (data not shown). Clearly, all nine $H$. contortus genotypes and the other sequences of $H$. contortus in group B were distinctly separated from the four $\mathrm{H}$. placei defined as an outgroup (group A) with a mean score of $97.02 \%$ identity in the range $95.20 \%-98.70 \%$ (data not shown). In group B, some genotypes, (HCFLCH4V1AN1, HCFLSV7V3N1, and HCFLSV24V1IN1) were clustered in $H$. contortus obtained from goats (MH481574) and sheep (MH481598) in Ghana in the range $99.10 \%-99.50 \%$ identity (mean $=99.23 \%)$ (data not shown). Additionally, it was discovered that $H$. contortus in Laos (HCFLCH17V1IN2) was related to a sequence of $H$. contortus in the USA (EU086390) with $96.10 \%$ identity (Table 7). However, there were no fixed nucleotide differences at 24, 205, and 219 for the $43 \mathrm{H}$. contortus sequences, compared with $H$. placei (data not shown).

\section{DISCUSSION}

Infection of Haemonchus species including $\mathrm{H}$. contortus in goats and sheep has been continually reported in many countries including in goats of Laos (Sato et al., 2014; Windsor et al., 2018). The current study recorded a similar proportion of adult male worms in goats $(66.02 \%)$ as reported by Vongnady et al. (2020b). Luang Prabang and Savannakhet provinces had the highest proportions of parasitic infection ( $67 \%$ ) with a high worm density in both provinces ( $48 \%)$. The prevalence of Haemonchus worms in Laos might be associated with the animal farm type and poor hygienic farm management, the chance of exposure to infective larvae, the lack of anthelmintics in smallholder systems, and poor veterinarian services (Windsor et al., 2018). Furthermore, humidity and temperature support larval growth, especially with the prevailing tropical monsoon climate of Laos (Wilson, 2007) that may influence parasite transmission, particularly during the rainy season when conditions are more favorable (Windsor et al., 2018). In addition, intensively raised animals may become exposed to the infective stages that may exist in pasture (Thomas et al., 2007; Windsor et al., 2018).

In the present study, three main vulvar morphs covered the three provinces with the knobbed vulvar morph type being the predominant form $(69.02 \%)$, followed by the linguiform and smooth morphs. A similar vulvar pattern has been reported by other researchers regarding Haemonchus spp. or H. contortus in goats (Gharamah et al., 2011; Akkari et al., 2013; Nahar et al., 2019), in sheep (Vadlejch et al., 2014; Badawy et al., 2015) and in both goats and sheep (Rahman \& Abd Hamid, 2007). Vongnady et al. (2020a) found the pattern in goats was slightly different but the knobbed form was still dominant. However, the present results are in contrast to other reports (Jacquiet et al., 1995; Thomas et al., 2007, Kumsa et al., 2008; Silva et al., 2015; Bibi et al., 2017; Sambodo et al., 2018) where the linguiform was dominant, although the smooth morphs were mostly detected in the lowest proportion, both in the current research and the studies by Gharamah et al. (2011), Badawy et al. (2015), Bibi et al. (2017), and Nahar et al. (2019). For sublinguiform Haemonchus females classified, the LB subtype was the most dominant among the five subtypes detected in Laos. This result was consistent 
Vongnady et al. (2021), Tropical Biomedicine 38(3): 294-310

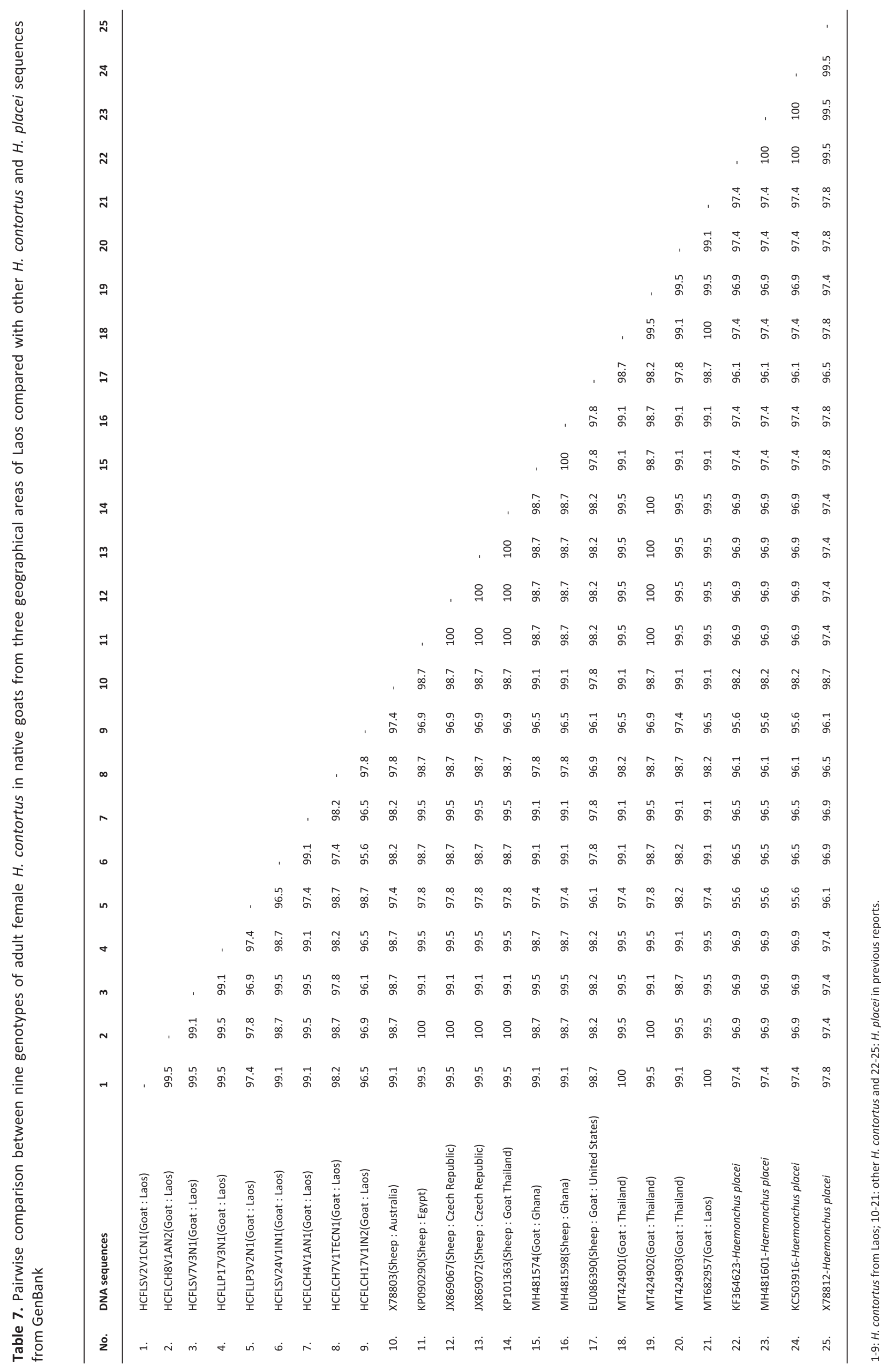


Vongnady et al. (2021), Tropical Biomedicine 38(3): 294-310

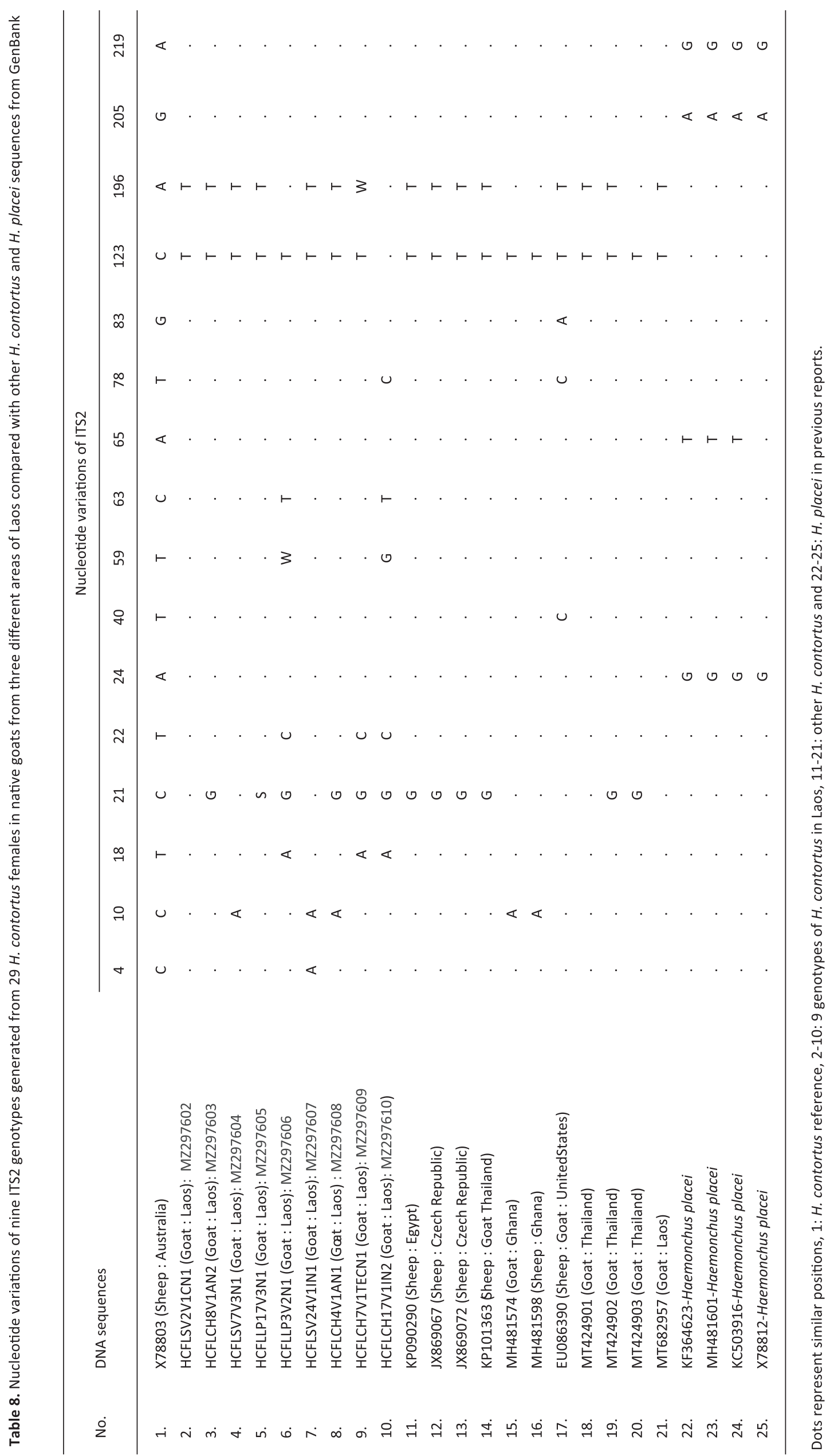


with Nahar et al. (2019) who reported LB was the dominant subtype in goats, while Kumsa et al. (2008), Akkari et al. (2013), Sambodo et al. (2018), and Vongnady et al. (2020a) recorded LA in goats as the most dominant. LC and LI were mostly found in low proportions both in the present study and in others (Kumsa et al., 2008; Sambodo et al., 2018; Vongnady et al., 2020a). However, the LC subtype reported by Thomas et al. (2007) in small ruminants seemed to be predominant. The LTEC subtype has to date only been recorded in goats in Thailand (Vongnady et al., 2020a) and Laos (the present study). We observed the appearance of high variation in the vulvar morphology of Haemonchus female in goats from different areas of Laos and this has been common in other studied areas. These variations in the vulvar morphs are probably caused by the ability of parasites to establish and develop when they are in animal hosts (Tod, 1965; Gharamah et al., 2011; Vadlejch et al., 2014; Bibi et al., 2017; Nahar et al., 2019). Some other factors might include the sample size (Nahar et al., 2019), individual host animals (Jacquiet et al., 1995), host species (Kumsa et al., 2008; Akkari et al., 2013), and the area being investigated. Because of polymorphisms in the vulvar shapes of each Haemonchus species, the use of these basic characters is probably not reliable as traits for species identification (Vadlejch et al., 2014; Silva et al., 2015; Lichtenfels et al., 1994; Vongnady et al., 2020a).

The pattern of cuticular ridges or synlophes described by Lichtenfels et al. (1986) and Lichtenfels et al. (1994) has been known as one of the most useful traits applied for species identification of trichostrongylids including Haemonchus spp. (Lichtenfels et al. 1994; Lichtenfels \& Pilitt, 2000; Gharamah et al., 2011; Silva et al., 2015). In the present study, the ridge patterns at the three main positions $\mathrm{EI}, 4$ $\mathrm{mm}$, and $\mathrm{MB}$ could distinguish Haemonchus spp. with various vulvar morphs. In addition, $100 \%$ of all selected specimens were identified as $\mathrm{H}$. contortus compared with the synlophe references (Table 2). However, the El region appeared to be the most valuable for identifying Haemonchus spp., giving the lowest variation in the number of cuticular ridges of $0.74 \%$ detected with only 29 ridges, as $99.26 \%$ of $H$. contortus females had a constant 30 ridges (Table 3 and 4). This was in agreement with Vongnady et al. (2020a, 2020b), and Silva et al. (2015) who applied this position to identify adult Haemonchus worms, while Lichtenfels et al. (1994) and do Amarante (2011) also considered that this position could discriminate among Haemonchus spp. in ruminants. For the region at $4 \mathrm{~mm}, 97.41 \%$ of female $H$. contortus from goats in Laos had 26 ridges, which was consistent with Rahman and Abd Hamid (2007), Vongnady et al. (2020a, 2020b) who reported on goats, while this result contrasted with reports by Lichtenfels et al. (1994) and Rahman and Abd. Hamid (2007) recorded in ruminants and sheep, respectively. At the MB of $H$. contortus, most specimens presented 22 ridges which was in accordance with Silva et al. (2015) who found mostly $99.68 \%$ (307/308) of female worms in sheep were $H$. contortus and showing only 22 ridges, and Vongnady et al. (2020a) reported a similar result. However, the use of all three positions of cuticular ridge patterns for identifying individual Haemonhus females at the same time might provide a more reliable result, particularly in serious cases in endemic areas. In addition, we observed the $4 \mathrm{~mm}$ and $\mathrm{MB}$ regions seemed to have high variations of ridges in all specimens detected, compared to the El region. A similar result was observed by Vongnady et al. (2020a) who reported at both positions (4 mm and $\mathrm{MB}$ region).

According to the variations in the numbers of extra cuticular ridges observed and the variation from a consistent, constant number $(30,26$, and 22 ridges for $\mathrm{El}, 4 \mathrm{~mm}$, and $\mathrm{MB}$, respectively) for female $H$. contortus in Laos, we investigated these variable ridges using PCR-based identification and this confirmed the individuals were all $H$. contortus. Thus, the numbers of ridges of $\mathrm{H}$. contortus females collected from goats in Laos at El, $4 \mathrm{~mm}$, and $\mathrm{MB}$ could be in the ranges 29-30, 25-27, and 21-23 ridges, respectively, with showing their variations in each position. Generally, the numbers of cuticular ridges are somewhat constant and uniform in each species including Haemonchus spp. (Lichtenfels et al., 1986; Lichtenfels \& Pilitt, 2000), but small variations in cuticular ridge patterns possibly occur between populations such as Haemonchus populations from divergent areas (Lichtenfels et al., 1986; Lichtenfels \& Pilitt, 2000; Dajem et al., 2019). In the present research, we found the median numbers of cuticular ridges at the same positions of female worms from each province of Laos were not significantly different, and the number of ridges was rather constant (Table 6). However, variations in the number of ridges in cross sections for each position on the female $H$. contortus in the present study might have been caused by short/minor gaps in the ridges or by an extra piece of cuticular ridge, perhaps resulting in incorrect identification (Lichtenfels et al., 1994; Lichtenfels \& Pilitt, 2000; Bibi et al., 2017).

The ITS2 marker is appropriate for showing a conserved region presenting low intra variation (Gasser et al., 1994; Gasser \& Newton, 2000; Kandil et al., 2017), and it is recognized as a reliable tool for species identification, particularly of trichostrongylids in ruminants including $H$. contortus and $H$. placei as their morphologies are more similar (Stevenson et al., 1995; Schnieder et al., 1999; Cerutti et al., 2010). In the present research, we proved all $H$. contortus genotypes based on ITS2 sequence analysis compared with reference sequences of $H$. contortus available in GenBank via three main analyses, namely analysis of nucleotide polymorphisms, comparative sequence identities, and genetic relationships using NJ tree. Based on the analysis of nucleotide polymorphisms shown in Table 8, we confirmed all genotypes as $H$. contortus due to the interspecies variation sites of the ITS2 sequences presenting at the differences of fixed nucleotides at positions 24, 205, and 219 between $H$. contortus and $H$. placei while $H$. placei had only the nucleotides G, A, and G for positions 24, 205, and 219, respectively. These findings were in accordance with works by Stevenson et al. (1995), Abramatov et al. (2013), Mangkit et al. (2014), Vadlejch et al. (2014), Ali et al. (2015), Chaudhry et al. (2015), Dey et al. (2019), and Vongnady et al. (2020a, 2020b). The pairwise comparison analysis shown in Table 7 , demonstrated that all $H$. contortus genotypes obtained from Laos compared with other $H$. contortus from GenBank had a mean identity score of $98.74 \%$, while compared with the ITS2 sequences of $H$. placei, they had an average identity score of $96.60 \%$. These values indicated that all genotypes were more related with several $H$. contortus sequences than with $H$. placei. In addition, we confirmed all $H$. contortus genotypes based on the NJ tree as shown in Figure 5 at the large scale of ITS2 $H$. contortus sequences obtained from heterologous hosts (goats, sheep, cattle, giraffe, wild blue sheep, and human beings) and several countries. This tree analysis showed that all the $H$. contortus genotypes from Laos in group B were more related with all $H$. contortus sequences compared to the $H$. placei sequences. Some genotypes of this tree were rather variable; for example, HCFLSV24V1IN1 seemed to be more distinct than others due to having only one nucleotide base (A) presented at position 4, compared with all the $H$. contortus samples analyzed. Likewise, genotypes of HCFLSV24V1IN1 and the two genotypes HCFLSV7V3N1 and HCFLCH4V1AN1 clustered with two $H$. contortus sequences from 
Ghana were distinguished from the other $H$. contortus because nucleotide base position 10 presented (Table 8). The HCFLCH17V1IN2 genotype was grouped with $H$. contortus from the USA (EU086390) and had only base $C$ at nucleotide position 78. However, these four genotypes as well as the other $\mathrm{H}$. contortus sequences did not contain base $\mathrm{G}, \mathrm{A}$, and $\mathrm{G}$ at positions 24, 205, and 219, respectively as stated earlier for $H$. placei. Thus, we also confirmed that all the genotypes are a mono species, $H$. contortus obtained from the $\mathrm{NJ}$ analysis. Based on the important information derived from NJ regarding the relationship between the $H$. contortus genotypes of Laos and other ruminants as well as humans associated with some issues particularly in parasite control and decreasing infection risk for this parasite in Laos, we suggested the importation of live goats from other countries, especially from Thailand (Windsor et al., 2017) or the allowing the movement of animals between provinces only after being treated or cleaned to remove parasites prior to entering new areas. This could include ensuring an effective control program regarding ruminants in Laos (such as beef cows and goats) should be carried out appropriately, while farmers should be made aware of parasitic zoonosis as happened to a human who became infected with $H$. contortus in Iran (Ghadirian \& Arfaa, 1973) due to the close contact between farmers and their goats.

Beside species identification based on Haemonchus males, the detection of female Haemonchus worms using cuticular ridge pattern could benefit epidemiological investigations of Haemonchus worms in native goats of Laos. However, the occurrence of variations in the numbers of ridges between the different components of the Haemonchus spp. population during the diagnosis might contribute to species misidentification. Thus, other appropriate approaches should be applied to confirm the species. Further studies could include investigating the genetic diversity of Haemonchus species and in particular female $H$. contortus populations. Another useful topic could be studying the anthelmintic drug resistance of female $H$. contortus with different vulvar morphs from various areas of Laos.

\section{CONCLUSION}

This was the first study in Laos to identify adult female Haemonchus spp. in native goats using the cuticular ridge pattern. The results revealed this character could be useful for species identification and is a potential alternative means when adult male worms might be incomplete or only undesirable specimens are available or both, with the goal of enhancing the effective control of these parasites in Laos. Based on this character, $H$. contortus having polymorphisms in vulvar morphology is a dominant species distributed in the three provinces of Laos that were sampled. Perhaps this dangerous species is spreading throughout the country with the El position offering greater promise for an accurate identification compared to the other positions. However, although this inexpensive tool has provided valuable information on cuticular ridges for identifying adult female Haemonchus worms, being particularly valuable in parasite control strategies, some doubtful samples and variation in the number of ridges still mean there will be an ongoing need for highly specific techniques such as PCR.

\section{ACKNOWLEDGMENTS}

The Faculty of Veterinary Technology, Kasetsart University, Thailand provided support facilities and technical help. Dr. Somphong Chanthavong, the Dean of the Faculty of Agriculture and Environment, Savannakhet University, Laos offered his support and help. The relevant smallholder goat farmers, particularly Mr. Soukvilay Yomsamon and Mr. Xaykham Onphachan in Laos assisted with parasite collection and staff from the Faculty of Agriculture and Environment, Savannakhet University provided support and technical help. Asst. Prof. Dr. Mereerat Manwong provided valuable assistance with the statistical analysis and Mr. Phonepasith Phongdala helped to create the map of Laos, and The Kasetsart University Research and Development Institute (KURDI), Bangkok, Thailand provided English editing assistance. Financial support was obtained through the Kasetsart University Scholarship for ASEAN for Commemoration of the $60^{\text {th }}$ Birthday Anniversary of Professor Dr. Her Royal Highness Princess Chulabhorn Mahidol.

\section{Conflict of interests}

The authors declare that they have no conflicts of interest.

\section{REFERENCES}

Abramatov, M.B., Amirov, O.O., Kuchboev, A.E., Khalilov, I.M. \& Abdurakhmanov, I.Y. (2013). Morphological and molecular characterization of Haemonchus contortus and $\mathrm{H}$. placei (Nematoda: Trichostrongylidae) from Uzbekistan by sequences of the second internal transcribed spacer of ribosomal DNA. Scientia Parasitologica 14: 115-120.

Achi, Y.L., Zinsstag, J., Yao, K., Yeo, N., Dorchies, P. \& Jacquiet, P. (2003). Host specificity of Haemonchus spp. for domestic ruminants in the savanna in northern Ivory Coast. Veterinary Parasitology 116: 151-158. https://doi.org/10.1016/ s0304-4017(03)00258-9

Akkari, H., Gharbi, M., Awadi, S., Mohamed, A.D. \& Kumsa, B. (2013). New sublinguiform vulvar flap of Haemonchus species in naturally infected domestic ruminants in Béja Abattoir, North Tunisia. Veterinarski Arhiv 82: 281-291.

Ali, Q., Rashid, M.I., Ashraf, K., Zahid, M.N., Ashraf, S. \& Chaudhry, U. (2015). Genetic variation in the rDNA ITS-2 sequence of Haemonchus placei from cattle host. Journal of Infection and Molecular Biology 3: 13-18. http://dx.doi.org/ 10.14737/journal.jimb/2015/3.1.13.18

Arsenopoulos, K.V., Fthenakis, G.C., Katsarou, E.I. \& Papadopoulos, E. (2021). Haemonchosis: A challenging parasitic infection of sheep and goats. Animals: an open access journal from MDPI 11: 363. https://doi.org/10.3390/ ani11020363

Badawy, A.I.I., Alzohairy, A.M., Abdel-Aziz, A., El-Nour, M.F.A. \& Elsayed, A.N. (2015). Morphological and molecular characterization of Haemonchus contortus (Rudolphi, 1803) Cobb, 1898 (Nematoda: Trichostrongyloidea) from sheep, Ovis aries in Egypt based on the second internal transcribed spacer of ribosomal DNA. International Journal of Advanced Research 3: 1152-1161.

Besier, R.B., Kahn, L.P., Sargison, N.D. \& Van Wyk, J.A. (2016). Diagnosis, treatment and management of Haemonchus contortus in small ruminants. Advances in Parasitology 93: 181-238. https://doi.org/10.1016/bs.apar.2016.02.024

Bibi, R., Afshan, K., Khan, I.A., Iqbal1 Z., Kayani, A.R., Mushtaq, M., Irfan, M., Qayyum, M. \& Hassan, M.F. (2017). Phenotyping and prevalence of Haemonchus contortus (Nematoda: Trichostongylidae) in ruminants from endemic areas of Pakistan: influence of host species and geographical area on phenotypic traits of worms. Pakistan Veterinary Journal 37: 170-174.

Burns, R., Douangngeun, B., Theppangna, W., Mukaka, M., Wegner, M.D., Windsor, P.A. \& Blacksell, S.D. (2019). Peste des petits ruminants (PPR) virus serological surveillance 
in goats in Lao PDR: Issues for disease eradication in a low-resource disease-free setting. Transboundary and Emerging Diseases 66: 939-947. https://doi.org/10.1111/ tbed.13109

Cerutti, M.C., Citterio, C.V., Bazzocchi, C., Epis, S., D’Amelio, S., Ferrari, N. \& Lanfranchi, P. (2010). Genetic variability of Haemonchus contortus (Nematoda: Trichostrongyloidea) in alpine ruminant host species. Journal of Helminthology 84: 276-283. https://doi.org/10.1017/S0022149X09990587

Chaudhry, U., Redman, E.M., Abbas, M., Muthusamy, R., Ashraf, K. \& Gilleard, J.S. (2015). Genetic evidence for hybridisation between Haemonchus contortus and Haemonchus placei in natural field populations and its implications for interspecies transmission of anthelmintic resistance. International Journal for Parasitology 45: 149-159. https:// doi.org/10.1016/j.ijpara.2014.09.002

Craig, T.M. (2018). Gastrointestinal nematodes, diagnosis and control. Veterinary Clinics of North America: Food Animal Practice 34: 185-199. https://doi.org/10.1016/j.cvfa.2017. 10.008

Dajem, S., Morsy, K., Al-Kahtani, M. \& Abdel-Gaber, R. (2019). Taxonomic justification of the pathogenic strongylid infecting the Arabian Camel Camelus dromedarius as Haemonchus Longistipes by morphological and molecular phylogeny. Journal of Veterinary Research 63: 51-61. https:// doi.org/10.2478/jvetres-2019-0019

Dey, A.R., Zhang, Z., Begum, N., Alim, M.A., Hu, M. \& Alam, M.Z. (2019). Genetic diversity patterns of Haemonchus contortus isolated from sheep and goats in Bangladesh. Infection, genetics and evolution: Journal of Molecular Epidemiology and Evolutionary Genetics in Infectious Diseases 68: 177-184. https://doi.org/10.1016/j.meegid.2018.12.021

do Amarante, A.F. (2011). Why is it important to correctly identify Haemonchus species?. Revista brasileira de parasitologia veterinaria = Brazilian journal of veterinary parasitology: Orgao Oficial do Colegio Brasileiro de Parasitologia Veterinaria 20: 263-268. https://doi.org/10.1590/s198429612011000400002

Douanne, N., Wagner, V., Bélanger, D. \& Fernandez-Prada, C. (2019). High-throughput identification and quantification of Haemonchus contortus in fecal samples. Veterinary Parasitology 265: 24-28. https://doi.org/10.1016/j.vetpar. 2018.11.017

Eysker, M. \& Ploeger, H.W. (2000). Value of present diagnostic methods for gastrointestinal nematode infections in ruminants. Parasitology 120: S109-S119. https://doi.org/ $10.1017 / \mathrm{s} 0031182099005752$

Gasser, R.B., Chilton, N.B., Hoste, H. \& Stevenson, L.A. (1994). Species identification of trichostrongyle nematodes by PCR-linked RFLP. International Journal for Parasitology 24: 291-293. https://doi.org/10.1016/0020-7519(94)90041-8

Gasser, R.B. \& Newton, S.E. (2000). Genomic and genetic research on bursate nematodes: significance, implications and prospects. International Journal for Parasitology 30: 509534. https://doi.org/10.1016/s0020-7519(00)00021-7

Ghadirian, E. \& Arfaa, F. (1973). First report of human infection with Haemonchus contortus, Ostertagia ostertagi, and Marshallagia marshalli (family Trichostrongylidae) in Iran. The Journal of Parasitology 59: 1144-1145.

Gharamah, A.A., Azizah, M.N. \& Rahman, W.A. (2012). Genetic variation of Haemonchus contortus (Trichostrongylidae) in sheep and goats from Malaysia and Yemen. Veterinary Parasitology 188: 268-276. https://doi.org/10.1016/ j.vetpar.2012.04.003

Gharamah, A.A., Rahman, W.A. \& Azizah, M.N.S. (2011). Morphological characterization of Haemonchus contortus in sheep (Ovis aries) and goats (Capra hircus) from two
Governorates in Yemen. World Journal of Zoology 6: 263267.

Gharamah, A.A., Rahman, W.A. \& Nor, S.A.M. (2011). Phenotypic differences of Haemonchus contortus from sheep and goats in the States of Perak and Kelantan, Peninsular Malaysia. Acta Parasitologica 56: 412-417. https://doi.org/10.2478/ s11686-011-0080-4

Hall, T.A. (1999). BioEdit: A user-friendly biological sequence alignment editor and analysis program for Windows 95/ 98/NT. Nucleic Acids Symposium Series 41: 95-98.

Hegde, N.G. (2020). Goat development: An opportunity to strengthen rural economy in asia and africa. Asian Journal of Research in Animal and Veterinary Sciences 5: 30-47.

Höglund, J., Elmahalawy, S.T., Halvarsson, P. \& Gustafsson, K. (2019). Detection of Haemonchus contortus on sheep farms increases using an enhanced sampling protocol combined with PCR based diagnostics. Veterinary Parasitology: X 2: 100018. https://doi.org/10.1016/j.vpoa. 2019.100018

Jacquiet, P.H., Cabaret, J., Cheikh, D. \& Thiam, E. (1997). Identification of Haemonchus species in domestic ruminants based on morphometrics of spicules. Parasitology Research 83: 82-86. https://doi.org/10.1007/ s004360050213

Jacquiet, P., Humbert, J.F., Comes, A.M., Cabaret, J., Thiam, A. \& Cheikh, D. (1995). Ecological, morphological and genetic characterization of sympatric Haemonchus spp. parasites of domestic ruminants in Mauritania. Parasitology 110: 483-492. https://doi.org/10.1017/s0031182000064829

Kandil, O.M., Abdelrahman, K.A., Fahmy, H.A., Mahmoud, M.S., El Namaky, A.H. \& Miller, J.E. (2017). Phylogenetic patterns of Haemonchus contortus and related trichostrongylid nematodes isolated from Egyptian sheep. Journal of Helminthology 91: 583-588. https://doi.org/10.1017/ S0022149X16000687

Kotze, A.C. \& Prichard, R.K. (2016). Anthelmintic Resistance in Haemonchus contortus: History, mechanisms and diagnosis. Advances in Parasitology 93: 397-428. https://doi.org/10.1016/ bs.apar.2016.02.012

Kumar, S., Stecher, G. \& Tamura, K. (2016). MEGA7: Molecular evolutionary genetics analysis version 7.0 for bigger datasets. Molecular Biology and Evolution 33: 1870-1874. https://doi.org/10.1093/molbev/msw054

Kumsa, B., Tolera, A. \& Abebe, R. (2008). Vulvar morphology and sympatry of Haemonchus species in naturally infected sheep and goats of Ogaden region, eastern Ethiopia. Veterinarski Arhiv 78: 331-342.

LeJambre, L.F. \& Whitlock, J.H. (1968). Seasonal fluctuation in linguiform morphs of Haemonchus contortus cayugensis. The Journal of Parasitology 54: 827-830.

Lichtenfels, J.R., Pilitt, P.A. \& Hoberg, E.P. (1994). New morphological characters for identifying individual specimens of Haemonchus spp. (Nematoda: Trichostrongyloidea) and a key to species in ruminants of North America. The Journal of Parasitology 80: 107-119.

Lichtenfels, J.R., Pilitt, P.A. \& Le Jambre, L.F. (1986). Cuticular ridge patterns of Haemonchus contortus and Haemonchus placei (Nematoda: Trichostrongyloidea). Proceedings of the Helminthological Society of Washington 53: 94-101.

Lichtenfels, J.R., Pilitt, P.A. \& Le Jambre, L.F. (1988). Spicule lengths of the ruminant stomach nematodes Haemonchus contortus, Haemonchus placei, and their hybrids. Proceedings of the Helminthological Society of Washington 55: 97-100.

Lichtenfels, J.R. \& Pilitt, P.A. (2000). Synlophe patterns of the Haemonchinae of ruminants (Nematoda: Trichostrongyloidea). The Journal of Parasitology 86: 1093-1098. https://doi.org/10.1645/0022-3395(2000)086[1093:SPOTHO] 2.0.CO;2 
Ljungström, S., Melville, L., Skuce, P.J. \& Höglund, J. (2018). Comparison of four diagnostic methods for detection and relative quantification of Haemonchus contortus eggs in feces samples. Frontiers in Veterinary Science 4: 239. https://doi.org/10.3389/fvets.2017.00239

MAFF (Ministry of Agriculture, Fisheries and Food). (1971). Manual of Veterinary Parasitological Laboratory Techniques, London: HM Stationery Oce.

Mangkit, B., Thaenkham, U., Adisakwattana, P., Watthanakulpanich, D., Jantasuriyarat, C. \& Komalamisra, C. (2014). Molecular characterization of Haemonchus contortus (Nematoda: Trichostrongylidae) from small ruminants in Thailand based on the second internal transcribed spacer of ribosomal DNA. Kasetsart Journal (Natural Science) 48: 740-758.

Monteiro, A., Costa, J.M. \& Lima, M.J. (2018). Goat system productions: Advantages and disadvantages to the animal, environment and farmer. Goat Science. http:// dx.doi.org/10.5772/intechopen.70002

Nahar, L., Sarder, M.J.U., Rahman, M., Begum, M.I.A. \& Rahman, S. (2019). Vulvar flap morphology of Haemonchus contortus in naturally infected slaughtered goats in Northern area of Bangladesh. Bangladesh Journal of Veterinary Medicine 17: 125-131. https://doi.org/10.33109/bjvmjd19rm2

Peter, J.W. \& Chandrawathani, P. (2005). Haemonchus contortus: Parasite problem no. 1 from tropics-Polar Circle. Problems and prospects for control based on epidemiology. Tropical Biomedicine 22: 131-137.

Rahman, W.A. \& Abd Hamid, S. (2007). Morphological characterization of Haemonchus contortus in goats (Capra hircus) and sheep (Ovis aries) in Penang, Malaysia. Tropical Biomedicine 24: 23-27.

R Core Team. (2019). R: A language and environment for statistical computing. Vienna: R Foundation for Statistical Computing.

Roberts, F.H.S., Turner, H.N. \& Mckevett, M. (1954). On the specific distinctness of the ovine and bovine strains of Haemonchus contortus (Rudolphi) Cobb (Nematoda: Trichostrongylidae). Australian Journal of Zoology 2: 275-295. https://doi.org/10.1071/ZO9540275

Rose, J.H. (1966). The vulval flap formula of Haemonchus contortus from sheep in South east England. Research in Veterinary Science 7: 480-483.

Salle, G., Doyle, S.R., Cortet, J., Cabaret, J., Berriman, M., Holroyd, N. \& Cotton, J.A. (2019). The global diversity of Haemonchus contortus is shaped by human intervention and climate. Nature Communications 10: 4811. https:// doi.org/10.1038/s41467-019-12695-4

Sambodo, P., Prastowo, J., Indarjulianto, S. \& Kurniasih, K. (2018). Morphology and morphometry of Haemonchus contortus in goats in Yogyakarta, Indonesia. Jurnal Kedokteran Hewan 12: 62-65.

Sato, M.O., Sato, M., Chaisiri, K., Maipanich, W., Yoonuan, T., Sanguankiat, S., Pongvongsa, T., Boupha, B., Moji, K. \& Waikagul, J. (2014). Nematode infection among ruminants in monsoon climate (Ban-Lahanam, Lao PDR) and its role as food-borne zoonosis. Revista Brasileira de Parasitologia Veterinaria $=$ Brazilian Journal of Veterinary Parasitology: Orgao Oficial do Colegio Brasileiro de Parasitologia Veterinaria 23: 80-84. https://doi.org/10.1590/s1984-29612014011

Schnieder, T., Heise, M., \& Epe, C. (1999). Genus-specific PCR for the differentiation of eggs or larvae from gastrointestinal nematodes of ruminants. Parasitology Research 85: 895-898. https://doi.org/10.1007/s004360050654

Selemon, M. (2018). Review on control of Haemonchus contortus in sheep and goat. Journal of Veterinary Medicine and Research 5: 1139-1145.
Silva, M.R.L., Amarante, M.R.V., Bresciani, K.D.S. \& Amarante, A.F.T. (2015). Host-specificity and morphometrics of female Haemonchus contortus, $H$. placei and $H$. similis (Nematoda: Trichostrongylidae) in cattle and sheep from shared pastures in São Paulo State, Brazil. Journal of Helminthology 89: 302-306. https://doi.org/10.1017/S0022149X14000078

Skapetas, B. \& Bampidis, V. 2016. Goat production in the world: Present situation and trends. Livestock Research for Rural Development 28: 200.

Soulsby, E.J.L. (1982). Helminthes, arthropods and protozoa of domesticated animals. 7th edition. London: Bailliere Tindall.

Stevenson, L.A., Chilton, N.B. \& Gasser, R.B. (1995). Differentiation of Haemonchus placei from $\mathrm{H}$. contortus (Nematoda: Trichostrongylidae) by the ribosomal DNA second internal transcribed spacer. International Journal for Parasitology 25: 483-488. https://doi.org/10.1016/00207519(94)00156-i

Suarez, V.H., Martínez, G.M., Viñabal, A.E. \& Alfaro, J.R. (2017). Epidemiology and effect of gastrointestinal nematodes on dairy goats in Argentina. Onderstepoort Journal of Veterinary Research 84: e1-e5. https://doi.org/10.4102/ ojvr.v84i1.1240

Thomas, N., Teshale, S. \& Kumsa, B. (2007). Abomasal nematodes of sheep and goats slaughtered in Awassa (Ethiopia): species composition, prevalence and vulvar morphology. Helminthologia 44: 70-75. https://doi.org/ 10.2478/s11687-007-0006-8

Tod, M.E. (1965). On the morphology of Haemonchus contortus (Rudolphi) Cobb (Nematoda: Trichostrogylidae) in sheep and cattle. Australian Journal of Zoology 13: 773-782. https://doi.org/10.1071/ZO9650773

Vadlejch, J., Lukesova, D., Vasek, J., Vejl, P., Sedlak, P., Cadkova, Z., Langrova, I., Jankovska, I. \& Salaba, O. (2014). Comparative morphological and molecular identification of Haemonchus species in sheep. Helminthologia 51: 130-140. https://doi.org/10.2478/s11687-014-0220-0

Vongnady, K., Rucksaken, R. \& Mangkit, B. (2020a). Morphological characters for identifying adult female Haemonchus species (Nematoda: Trichostrongyloidea) in naturally infected goats in Thailand. 50th National Graduate Research Conference. Bangkok, Thailand.

Vongnady, K., Rucksaken, R. \& Mangkit, B. (2020b). Morphological identification of adult male Haemonchus species in goats from Thailand and Lao PDR. Tropical Biomedicine 37: 691-712. https://doi.org/10.47665/tb.37.3.691

Wang, C., Li, F., Zhang, Z., Yang, X., Ahmad, A.A., Li, X., Du, A. \& $\mathrm{Hu}, \mathrm{M}$. (2017). Recent research progress in China on Haemonchus contortus. Frontiers in microbiology 8: 1509. https://doi.org/10.3389/fmicb.2017.01509

Wilson, R.T. (2007). Status and prospects for livestock production in the Lao People's Democratic Republic. Tropical animal Health and Production 39: 443-452. https:// doi.org/10.1007/s11250-007-9048-7

Windsor, P.A., Nampanya, S., Putthana, V., Keonam, K., Johnson, K., Bush, R.D. \& Khounsy, S. (2018). The endoparasitism challenge in developing countries as goat raising develops from smallholder to commercial production systems: A study from Laos. Veterinary Parasitology 251: 95100. https://doi.org/10.1016/j.vetpar.2017.12.025

Windsor, P.A., Nampanya, S., Tagger, A., Keonam, K., Gerasimova, M., Putthana, V., Bush, R.D. \& Khounsy, S. (2017). Is orf infection a risk to expanding goat production in developing countries? A study from Lao PDR. Small Ruminant Research 154: 123-128. https://doi.org/10.1016/ j.smallrumres.2017.08.003 